
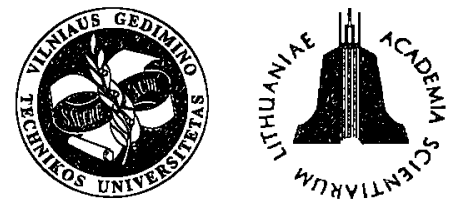

ISSN 1648-4142 TRANSPORT

http:/www.vtu.lt/english/editions

TRANSPORT - 2003, Vol XVIII, No 6, 255-258

\title{
FORECASTIVG OF RAILWAY FREIGHT VOLUME: APPROACH OF ESTONIAN RAILWAY TO ARISE EFFICIENCY
}

\author{
Ülo Hunt \\ Baltic Branch of International Academy of Noosphere, Raadiku 13-75, Tallinn, Estonia. E-mail: yloetekp@zzz.ee \\ Received 200306 06; accepted 20031114
}

\begin{abstract}
The local railroad was substantially deregulated and prepared for privatization by Estonian government in 90's. Changes in commodity mix, length of haul, shipment size, loading weight, equipment ownership, railroad costs, competition from other modes, and demand for railroad transportation have all played a significant role. This paper introduces the importance of forecasting a railway freight volume using the methodology of intemational knowledge.
\end{abstract}

Keywords: railroad, forecast, ARIMA, model.

\section{Introduction}

The Republic of Estonia has set the development of an integrated and competitive transport system as one of its goals. Taking into account the favourable position of Estonia pertaining to economic geography, the guideline of transport policy is the promotion of international transit traffic. Transport traders contribute more than $10 \%$ of the GNP of Estonia.

Estonia is one of the shortest and cheapest transit corridors between the CIS countries and Western Europe. Together with harbours, the railway represents the main link for transit through Estonia. Promotion of international railway trade is one of the most important priorities of Estonian economy. Of the total quantity of freight passing through Estonia, 42,1 million tons or more than $95 \%$ were conveyed by railway in 2002 .

Estonia is obliged to ensure smooth transit transport of goods through its territory on the level of internationally recognised service standards. In accordance with the growth rate economy of the neighbouring regions, the activity of the customers using the railway service is developing and becoming more active, as well.

\section{Efficiency and Competition}

More than ever Estonian Railways Ltd. has been able to acknowledge its role upon efficient servicing of customers, being primarily oriented to international transport market. Price formation and long-term customer contracts serve as the basis for the stable customer policy.

For the Baltic railways the competition between transport modes in freight market is not the issue of the first importance. The hard competition exists between the railway companies in the freight transit market.

As far as the Estonian Railway is concerned, we are the most competitive owing to the shortest leg and the lowest prices. However, new market conditions require using of new approach.

\section{Methodology}

Time series models were used for obtaining shortrun forecasts of railway fertilizer and timber traffic. The multiplicative seasonal autoregression integrated moving average (ARIMA) model is among these models.

The time series considered in this article are the sequences of observations observed at equally spaced intervals. The time series can be considered as having three basic components:

1. Trend

2. Cyclic or periodic

3. Random or noise

The trend represents a long term pattern, e.g., increasing sales, while the cyclic or periodic components follow the patterns such as 'summer sales are higher than winter sales' or 'there are more enquires on a Monday morning than on a Friday afternoon'. The random component is the fluctuation around the trend and cycles. Unlike regression models, the noise in time series models is not assumed to be independent but is (auto) correlated. Furthermore, the noise is usually assumed to have a zero mean and to be stationary. Being stationary means that the statistical relationship between the observations at time $t$ and time $t+l$ is the same as the statistical relationship between the observations at time $t+t$ and $t+l+\tau$. The relationship can be described in the terms of either their joint distribution or in the terms of corre- 
lation. The theoretical correlation between the observation at time $t$ and the observation at time $t+l$, that is at lag $l$ is denoted by $\rho l$.

Statistical models for time series relate the correlated noise (denoted by $w t$ ) to an independent random component or white noise (denoted by et ), and hence explain the autocorrelation $r l$. The most common models for stationary time series are autoregressive models and moving average models. An auto-regressive model for a series $w t$ of order $p$ is:

$$
w_{t}=\Phi_{1} w_{t-1}+\Phi_{2} w_{t-2}+\ldots+\Phi_{p} w_{t-p}+\varepsilon t
$$

which is denoted by AR ( $\rho$ ). A moving average model of order $q$ is:

$$
w_{2}=\varepsilon t-\theta_{1} \varepsilon_{t-1}-\theta_{2} \varepsilon_{t-2}-\ldots-\theta_{q} \varepsilon_{t-q},
$$

which is denoted by $\operatorname{MA}(q)$. The difference between the two forms of the model is that the autocorrelation for an autoregressive model gradually dies away while the autocorrelation for a moving average model will cut off at lag $q$.

In the situation where the data has cyclic or periodic nature, for example days of the week, a seasonal model may be appropriate. For example, Tuesday's observation may be related to both Monday's observation and the previous Tuesday's observation. In seasonal models the terms are related to the seasonality, $s$, e.g., for days of the week $s=7$. The seasonal autoregressive and moving average models are:

$$
w_{t}=\Phi_{1} w_{t-s}+\Phi_{2} w_{t-2 s}+\ldots+\Phi_{p} w_{t-p s}+\varepsilon t
$$

and

$$
w_{2}=\varepsilon_{t}-\theta_{1} \varepsilon_{t-s}-\theta_{2} \varepsilon_{t-2 s}-\ldots-\theta_{Q} \varepsilon_{t-Q} .
$$

These models can be combined to give a seasonal ARMA model

$$
\begin{aligned}
& w_{t}=\Phi_{1} w_{t-s}+\Phi_{2} w_{t-2 s}+\ldots+\Phi_{P} w_{t-P s}+e_{t}- \\
& \Theta_{1} e_{t-s}-\Theta_{2} e_{t-2 s}-\ldots-\Theta_{Q} e_{t-Q s}, \\
& e_{t}=\phi_{1} e_{t-1}+\phi_{2} e_{t-2}+\ldots+\phi_{p} e_{t-p}+\varepsilon_{t}-\theta_{1} \varepsilon_{t-1}- \\
& \theta_{2} \varepsilon_{t-2}-\theta_{q} \varepsilon_{t-q},
\end{aligned}
$$

where $e_{t}$ is an intermediate series for the purposes of defining the model.

In the situation where the series $y_{t}$ is not stationary it may be possible to make it stationary by applying differencing or seasonal differencing. First-order differencing is given by

$$
\nabla y_{t}=y_{t}-y_{t-1}
$$

and first-order seasonal differencing is given by

$$
\nabla_{s} y_{t}=y_{t}-y_{t-1} \text {. }
$$

Differencing can be combined with a constant term to give

$$
\nabla_{d} \nabla_{s D} y_{t}=c+w_{t}
$$

Combining this with the $A R M A$ model given above gives a seasonal $A R I M A$ (AutoRegressive Integrated Moving Average) model which can be specified by seven values $(p, d, q, P, D, Q, s)$.

\section{Time Series Model Identification}

The basic tools in the identification of a suitable time series model are data plots, the autocorrelation function (acf) and the partial autocorrelation function (pacf). Plotting the data will indicate if the series is stationary. If not, the series can be transformed using standard functions such as LOG or SQRT and differencing can be applied using function TIME_SERIES_DIFF. Given a stationary time series, the acf and pacf can be calculated using the functions $\mathrm{ACF}$ and PACF respectively. By looking at acf the order, $q$ of a possible MA model can be identified, while the pacf for an AR $(p)$ model will cut off at lag $p$.

The function PACF also gives approximate estimates of the parameters of the autoregressive model of order given by the number of partial autocorrelations requested and the predictor error variance ratio which is

$$
V_{l}=\operatorname{var}\left(\varepsilon_{l, t}\right) / \operatorname{var}\left(w_{t}\right),
$$

where $\operatorname{var}\left(w_{t}\right)$ is the variance of the stationary series and $\operatorname{var}\left(\varepsilon_{l, t}\right)$ is the estimated variance of the white noise when $\mathbf{A R}(l)$ has been fitted.

If neither approach is suitable then ARMA models can be considered. The function ARIMA_APPROX FIT gives an approximate fit for an $A R I M A$ model. This may be useful in model identification or for giving a set of initial values for the full fitting process.

\section{Time Series Model Fitting and Forecasting}

The function ARIMA_FIT fits an ARIMA model using either maximum likelihood or the least squares. The model is specified by the orders $p, d, q, P, D, Q$ and $s$. The function returns the parameter estimates, standard errors, $t$-values and significance. The results can be input into ARIMA_FORECAST to forecast values for the series.

\section{Transfer Function Models}

The ARIMA model can be used to describe a single series; however, if the (output) series can be related to several input series then a multi-input or transfer function model can be used. The form of a transfer function model is

$$
y_{t}=z_{1, t}+z_{2, t}+\ldots+z_{m, t}+n_{t},
$$

where $n_{t}$ follows an ARIMA model and the components of the model, $z_{1, t}$, are related to the input variables, $x_{i, t}$, by either simple linear model, 


$$
z_{i, t}=\omega_{0} x_{i, t}
$$

or ARMA-like model

$$
\begin{aligned}
& z_{i, t}=\delta_{1} z_{i, t-1}+\delta_{2} z_{i, t-2}+\ldots+\delta_{p} z_{i, t-p}+\omega_{0} x_{i, t-b}+ \\
& \omega_{1} x_{i, t-b}-1+\ldots+\omega_{q} x_{i, t-b-q}
\end{aligned}
$$

where $b$ is known as the delay. A transfer function model can be fitted using the options of ARIMA FIT, and forecasts can be made using TRNS FUNC FORECAST. To forecast the output series of a transfer function model the forecasts of the input series has to be provided. Also, if the input series have been forecast using ARIMA models, these models may be supplied to TRNS_FUNC_FORECAST; this will not affect the forecast, but will adjust the forecast standard error.

The major concern here is that the residuals are systematically distributed across the series (e.g., they could be negative in the first part of the series and approach a zero in the second part) or that they contain some serial dependency which may suggest that the ARIMA model is inadequate. The analysis of ARIMA residuals constitutes an important test of the model. The estimation procedure assumes that the residuals are not (auto-) correlated and that they are normally distributed.

The ARIMA method is appropriate only for a time series that is stationary (i.e., its mean, variance, and autocorrelation should be approximately constant through time) and it is recommended when there are at least 50 observations in the input data. It is also assumed that the values of the estimated parameiters are constant throughout the series.

The showed methodology united with other approaches of a statistical analysis will give the establishment for the calculation of several estimation data for "describing better future".

\section{Model, Data and Resulits}

We try to use next statistical data for short-term forecasting of fertilizers and timber traffic. Data til 2002-12 is actual and the rest is forecast (Table 1).

We use for forecasting the next ARIMA model values (Table 2).

The working model gives us the following estimation parameters (Table 3) for a forecasting model.

The result of a forecasting model is shown on the following charts. It is clear, that ARIMA seasonal model gives better results, than a traditional statistical trend model.

Forecasts standard errors are shown in the Table 4 below.

The model developed in this study had good forecasting accuracy on a month basis. Comparing this estimation with the real data for February 2003 we have got

\begin{tabular}{|c|c|c|c|c|c|}
\hline TIme & Fertlizers & Timber & Time & Fertilizers & Timber \\
\hline 1996-1 & 110.773 & 56.829 & $2000-1$ & 206.976 & 81.025 \\
\hline $1996-2$ & 79.516 & 55.190 & $2000-2$ & 257.892 & 113.821 \\
\hline $1996-3$ & 116.655 & 63.306 & $2000-3$ & 152.249 & 144.178 \\
\hline $1996-4$ & 70.355 & 48.034 & $2000-4$ & 134.179 & 123.979 \\
\hline $1996-5$ & 21.597 & 45.347 & $2000-5$ & 82.641 & 97.051 \\
\hline $1996-6$ & 33.646 & 46.725 & $2000-6$ & 126.621 & 70.609 \\
\hline $1996-7$ & 13.340 & 46.469 & $2000-7$ & 179.958 & 87.571 \\
\hline $1996-8$ & 18.533 & 41.720 & $2000-8$ & 121.002 & 62.170 \\
\hline $1996-9$ & 37.497 & 35.758 & $2000-9$ & 116.674 & 55.094 \\
\hline $1996-10$ & 34.030 & 41.526 & $2000-10$ & 66.623 & 63.199 \\
\hline 1996-11 & 90.049 & 37.817 & $2000-11$ & 100.540 & 70.724 \\
\hline $1996-12$ & 81.079 & 39.675 & $2000-12$ & 197.236 & 76.090 \\
\hline 1997-1 & 73.388 & 45.147 & $2001-1$ & 200.298 & 100.034 \\
\hline 1997-2 & 120.317 & 62.896 & $2001-2$ & 227.782 & 108.499 \\
\hline $1997-3$ & 109.578 & 84.336 & $2001-3$ & 204.607 & 139.737 \\
\hline $9997-4$ & 68.467 & 87.533 & $2001-4$ & 175.703 & 125.736 \\
\hline $1997-5$ & 69.592 & 77.406 & $2001-5$ & 156.753 & 93.221 \\
\hline $9997-6$ & 32.024 & 76.079 & $2009-6$ & 119.882 & 67.455 \\
\hline $1997-7$ & 14.432 & 73.331 & $2009-7$ & 155.738 & 49.494 \\
\hline $1997-8$ & 31.969 & 72.150 & $2009-8$ & 146.721 & 56.230 \\
\hline $1997-9$ & 31.500 & 69.454 & 2004.9 & 205.981 & 62.212 \\
\hline $1997-10$ & 55.069 & 76.583 & $2001-10$ & 141.635 & 66.800 \\
\hline $1997-11$ & 104.699 & 62.778 & $2001-11$ & 229.258 & 60.029 \\
\hline $1997-12$ & 97.708 & 78.441 & $2001-12$ & 300.383 & 79.266 \\
\hline $1998-1$ & 126.820 & 72.826 & $2002-1$ & 412.332 & 87.584 \\
\hline $1996-2$ & 124.391 & 84.850 & $2002-2$ & 286.723 & 88.534 \\
\hline $1998-3$ & 116.367 & 108.960 & $2002-3$ & 260.961 & 112.219 \\
\hline $1998-4$ & 99.643 & 119.443 & $2002-4$ & 226.732 & 123.901 \\
\hline $1998-5$ & 43.655 & 901.105 & $2002-5$ & 198.674 & 91.871 \\
\hline $1998-6$ & 26.148 & 82.643 & $2002-6$ & 220.391 & 69.994 \\
\hline $1998-7$ & 18.489 & 64.182 & $2002-7$ & 132.656 & 58.213 \\
\hline $1998-8$ & 43.196 & 70.950 & $2002-8$ & 174.170 & 51.235 \\
\hline $1998-9$ & 54.566 & 59.959 & $2002-9$ & 179.126 & 70.875 \\
\hline $1998-10$ & 53.338 & 64.156 & $2002-10$ & 210.634 & 73.678 \\
\hline $9998-11$ & 100.021 & 65.854 & $2002-11$ & 182.526 & 86.659 \\
\hline $199 d-12$ & 179.587 & 90.311 & $2002-12$ & 248.614 & 90.119 \\
\hline 1999-1 & 151.344 & 82.329 & $2003-1$ & 323.870 & 101.733 \\
\hline $1999-2$ & 137.147 & 100.355 & 2003-2 & 292.061 & 103.294 \\
\hline $1999-3$ & 194.185 & 149.535 & $2003-3$ & 271.401 & 128.171 \\
\hline $1999-4$ & 131.628 & 148.444 & $2003-4$ & 241.480 & 132.850 \\
\hline $1999-5$ & 88.233 & 112.694 & 2003-5 & 219.042 & 100.293 \\
\hline $1999-6$ & 27.214 & B1.057 & 2003-6 & 208.484 & 77.139 \\
\hline $1999-7$ & 83.284 & 70.909 & $2003-7$ & 189.353 & 63.570 \\
\hline $1999-8$ & 80.422 & 64.345 & $2003-8$ & 202.885 & 59.879 \\
\hline $1999-9$ & 112.214 & 72.931 & 2003.9 & 237.959 & 75.983 \\
\hline $9999-10$ & 143.779 & 73.444 & $2003-10$ & 216.334 & 79.145 \\
\hline
\end{tabular}
the difference for timber $-12,3 \%$ and for fertilizer $+10,4 \%$.
Table 1. Data of forecasting and timber

Table 2. Values of ARIMA model

\begin{tabular}{|c|c|c|c|c|}
\hline \multicolumn{5}{|c|}{ Fertilizers } \\
\hline \multicolumn{5}{|c|}{ Parameter Estimates } \\
\hline \multicolumn{5}{|c|}{ Who } \\
\hline phi 1 & $-0,09499731$ & 0,39685723 & $-0,23937403$ & 0,81154633 \\
\hline phi 2 & 0,19079644 & 0,16059548 & 1,18805611 & 0,23900578 \\
\hline theta 1 & $-0,36692407$ & 0,38447241 & $-0,95435734$ & 0,34333345 \\
\hline Phi 1 & $-0,55435912$ & 0,13235746 & $-4,18834825$ & 8,392E-05 \\
\hline Constant & 28277,7675 & 4985,4818 & 5,67202301 & $3,2656 \mathrm{E}-07$ \\
\hline \multicolumn{5}{|c|}{ Timber } \\
\hline \multicolumn{5}{|c|}{ Parameter Estimates } \\
\hline phi 1 & 0,44779236 & 0,35085477 & 1,27628978 & 0,20625955 \\
\hline phi 2 & 0,21066067 & 0,26277443 & 0,80167875 & 0,42557299 \\
\hline theta 1 & $-0,23326823$ & 0.33071097 & $-0,70535377$ & 0,48303525 \\
\hline Phi 1 & $-0,25010224$ & 0,1459259 & $-1,7138989$ & 0,09117059 \\
\hline Constant & 5554,06845 & 4451,05719 & 1,24780883 & 0,2164446 \\
\hline
\end{tabular}

\begin{tabular}{|l|c|c|}
\hline \multicolumn{2}{|c|}{ ARIMA Model } \\
\hline Number of autoregressive terms & p & 2 \\
\hline Order of non-seasonal differencing & d & $\mathbf{Q}$ \\
\hline Number of moving average terms & $\mathbf{q}$ & 1 \\
\hline $\begin{array}{l}\text { Number of seasonal autoregressive } \\
\text { terms }\end{array}$ & $\mathbf{P}$ & $\mathbf{1}$ \\
\hline Order of seasonal differencing & $\mathbf{D}$ & 1 \\
\hline $\begin{array}{l}\text { Number of seasonal moving average } \\
\text { terms }\end{array}$ & $\mathbf{Q}$ & 0 \\
\hline The seasonality & $\mathbf{s}$ & 12 \\
\hline
\end{tabular}

Table 3. Results of simulation

However, because the residuals are assumed to be normally distributed, ARIMA models don't handle time series with irregular, large amplitude bursts very well. 


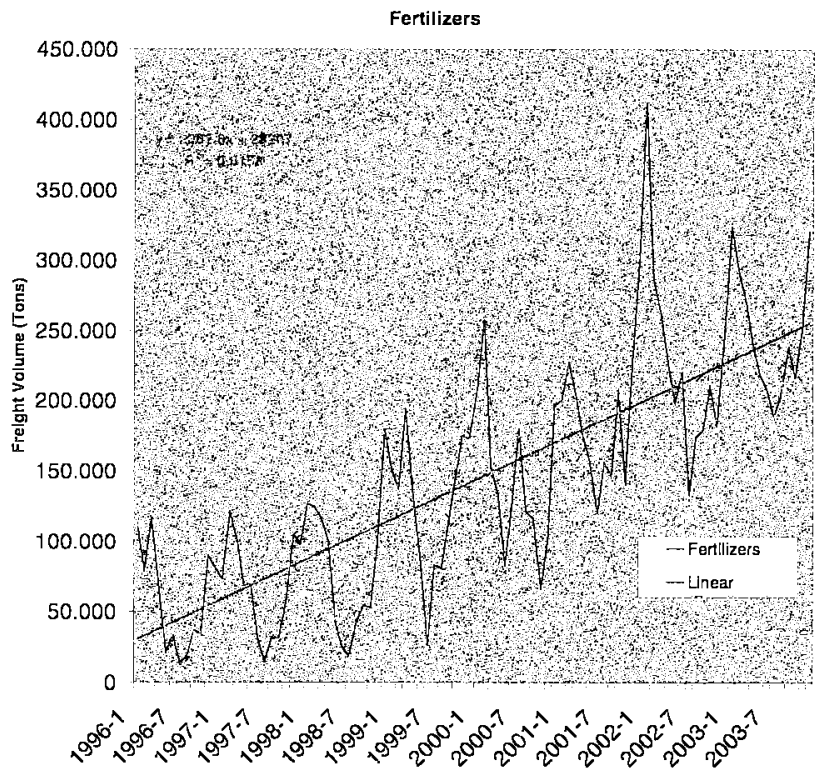

Fig 1. Forecasting fertilizers transport by rail

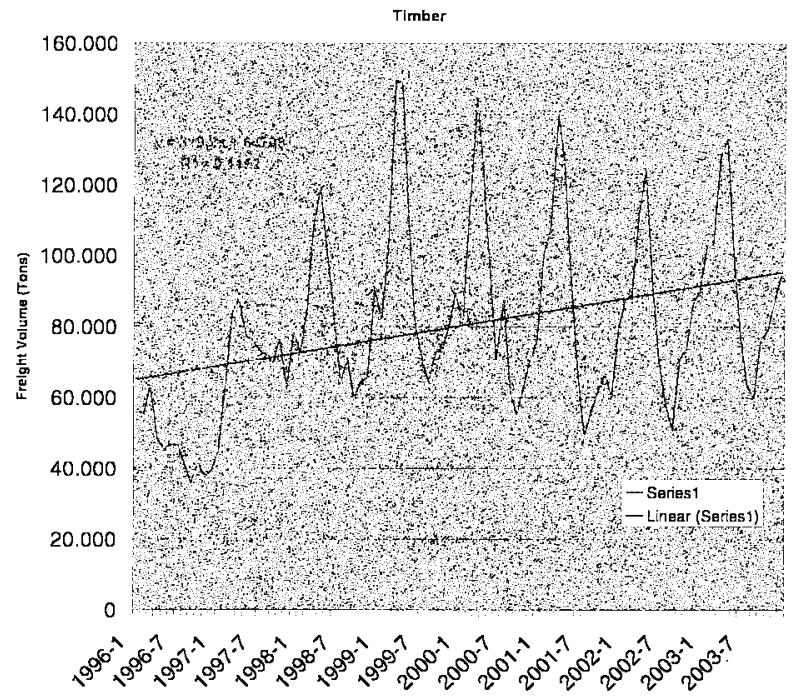

Fig 2. Forecasting timber transport by rail

Tabie 4. Forecasts standart errors

\begin{tabular}{|c|c|}
\hline $\begin{array}{l}\text { [Standard Errors of } \\
\text { Forecasts(12)| }\end{array}$ & $\begin{array}{l}\text { |Standard Errors of } \\
\text { Forecasts(12)| }\end{array}$ \\
\hline $40.821,7194$ & \begin{tabular}{|r|}
$12.754,9670$ \\
\end{tabular} \\
\hline $42.304,0691$ & $15.432,1581$ \\
\hline $42.836,6972$ & $16.775,1934$ \\
\hline 42.862 .1949 & $17.441,5726$ \\
\hline $42.877,4701$ & $17.793,9644$ \\
\hline $42.877,8204$ & $17.980,5814$ \\
\hline $42.878,2957$ & $18.080,6183$ \\
\hline $42.878,2979$ & $18.134,3394$ \\
\hline $42,878,3141$ & $18.163,2673$ \\
\hline $42.878,3141$ & $18.178,8562$ \\
\hline $42.878,3147$ & $18.187,2627$ \\
\hline $42.878,3147$ & $18.191,7971$ \\
\hline
\end{tabular}

Another area for further research is forecasting of other types of railway traffic such as petroleum prod- ucts, coal, grain and others. It would be interesting to observe the degree of temporal instability in the movement of these commodities. Finding of suitable models is necessary for railway traffic forecasts.

\section{Summary}

The tendencies shown at the last time in the development of the world economy, including the transport sector, witness their globalisation. The specialisation of different continents and regions in production is asking for more efforts for resolving the bottleneck issues in the world economy. New methods of analysis are welcome.

And the big business will set the requirements for the cargo to move. In the vast territories of Eurasia, where railways play the most important part in passenger and freight transport, the drawing of technically different railway networks closer to each other certain potentials for the development of connections between West and East. Estonian Railway is open to start partnership with all freight forwarders to increase its competitiveness on the market.

\section{Literature}

1. Aladjev, V. Z.; Veetõusme, R. A.; Hunt, Ü. J. General Theory of Statistics. Tallinn: TRG \& Salcombe Eesti Ltd., 1995. 201 p. (in Russian with English summary).

2. Aladjev, V. Z.; Hunt, Ü. J.; Shishakov, M.L. Course of the General Theory of Statistics. Ed. Acad. A. D. Ursul. Gomel: BELGUT Press, 1995. 201 p.

3. Hunt, Ü. J.; Shishakov, M. L; et al. Probability Theory and Mathematical Statistics. Ed. Acad. V. Z. Aladjev. Gomel: TRG, 1997. 180 p.

4. Hunt, Ü. J. Some Methods of Calculation of Carrying Capacity of the Rail-ways of the Baltic Region. In: Proc. Intern. Conf. TRANSBALTICA-99, April 1999. Vilnius, p. 392-398 (in Russian with English summary).

5. Hunt, Ü. J. Usage of new tariff model: Approach of Estonian Railway to arise efficiency. In: Proc. Intern. Conf. TRANSBALTICA-2002, April 2002, Vilnius, p. 214-220.

6. Aladjev, V. Z.; Hunt, Ü. J. A Workstation for mathematicians. In: Proc. of Conf. Improvement of Control Mechanism, April 1999, Grodno, p. 95-99 (in Russian with English summary).

7. Aladjev, V. Z; Hunt, Ü. J. A Workstation for mathematicians. In: Conf. TRANSBALTICA-99, April 1999, VTU, Vilnius, p. 392-395 (in Russian with extended English summary).

8. Michael, W.; Babcock, Xiaohua Lu. Forecasting inland waterway grain traffic. In: Transportation Research. Part E: Logistics and Transportation Review. V. 38, 2002, p. 65-74.

9. Statistical Add-Ins for Excel, User Guide. Second Edition. The Numerical Algorithms Group Limited, 2000.

10. Lucio Pompeo, Ted Sapountzis. Freight expetations. The McKinsey Quarterly, 2002, No 2.

11. Electronic Statistics Textbook. Tulsa, OK, StatSoft, Inc., 2002. 